\title{
Cana-de-açúcar em substituição ao feno de capim-tifton 85 em rações para cabras Saanen
}

[Sugar cane replacing grass hay tifton 85 in rations for Saanen goats]

\author{
A.M.D. Cabral ${ }^{1}$, A.M.V. Batista ${ }^{2}$, F.F.R. Carvalho ${ }^{2}$, A. Guim² ${ }^{2}$, G.L. Amorim ${ }^{3}$, \\ M.J.M.S. Silva ${ }^{4}$, A.A. França ${ }^{5}$, G.S. Belo Júnior ${ }^{6}$ \\ ${ }^{1}$ Programa Nacional de Pós-Doutorado da CAPES-UFRPE - Recife, PE \\ ${ }^{2}$ Universidade Federal Rural de Pernambuco - UFRPE - Recife, PE \\ ${ }^{3}$ Instituto Federal de Ciência e Tecnologia de Pernambuco - IFPE - Campus Vitória de Santo Antão, PE \\ ${ }^{4}$ Universidade Federal de Alagoas - UFAL - Maceió, AL \\ ${ }^{5}$ Universidade da Integração Internacional da Lusofonia Afro-Brasileira - UNILAB - Redenção, Ceará \\ ${ }^{6}$ Aluno de graduação - Universidade Federal de Pernambuco - UFPE - Recife, PE
}

\section{RESUMO}

Avaliou-se o consumo e digestibilidade dos nutrientes em dietas para cabras da raça Saanen arranjadas em um quadrado latino 5x5, alimentadas com cana-de-açúcar em substituição $(0,25,50,75$ e 100\%) ao feno de capimtifton 85. O experimento foi constituído de cinco períodos de 15 dias (10 dias para adaptação dos animais às dietas experimentais e 5 dias para coleta de dados e amostras). $\mathrm{O}$ consumo voluntário foi calculado pela diferença entre o ofertado e as sobras. Utilizou-se o óxido crômico para estimativa da produção de matéria seca fecal. A digestibilidade aparente da matéria seca, matéria orgânica, extrato etéreo e fibra em detergente neutro foi influenciada negativamente com a substituição, enquanto a digestibilidade da proteína e dos carboidratos não fibrosos não sofreu influência. $O$ baixo consumo de matéria seca de rações com cana-de-açúcar torna-se um fator limitante para cabras de média a alta produção de leite.

Palavras-chave: cabra, consumo, digestibilidade, matéria seca, nutrientes

\begin{abstract}
The intake and digestibility of nutrients in the diets of Saanen goats arranged in a 5x5 Latin square design, fed with sugar cane replacement (0, 25, 50, 75 and 100\%) hay Tifton 85 were evaluated. The experiment consisted of 5 periods of 15 days (10 days for animal adaptation to experimental diets and 5 days for data collection). The voluntary intake was calculated as the difference between the offered and leftovers. Digestibility chromic oxide was used to estimate the fecal dry matter production. The digestibility of dry matter, organic matter, ether extract and neutral detergent fiber was negatively influenced, whereas the digestibility of protein and non-fiber carbohydrates were not affected. The low dry matter intake of diets with sugar cane becomes a limiting factor for goats medium for high milk production.
\end{abstract}

Keywords: digestibility, dry matter, goats, intake, nutrients

\section{INTRODUÇÃO}

Dentre as forrageiras utilizadas para ruminantes, a cana-de-açúcar destaca-se como alimento alternativo (Castro et al., 2009), principalmente por apresentar alto potencial de produção no período em que as demais forrageiras encontramse escassas, destacando-se como planta de maior potencial para a produção de massa seca e energia por unidade de área em um único corte por ano. $\mathrm{O}$ valor nutritivo da cana-de-açúcar está diretamente correlacionado ao alto teor de açúcar na matéria seca (MS); no entanto, possui baixo teor de proteína e minerais, não sendo capaz de atender às necessidades de mantença dos ruminantes. Para suprir as deficiências nutricionais da cana-de-açúcar, a ureia tem sido utilizada como fonte de nitrogênio não proteico (NNP).

Recebido em 11 de fevereiro de 2014

Aceito em 9 de setembro de 2014

E-mail: amdcabral@gmail.com

Apoio financeiro: $\mathrm{CNPq}$ 
A cana-de-açúcar pode apresentar redução de consumo de matéria seca (CMS) ocasionada principalmente pela baixa digestibilidade da fibra que é lentamente utilizada, devido à maior fração indigestível da parede celular que permanece mais tempo no rúmen (Gonçalves et al., 2009). Porém, o tamanho reduzido da partícula melhora o aproveitamento dessa fração, visto que essa condição possibilita área favorável ao ataque das bactérias ruminais, havendo melhor interação entre tamanho das partículas e micro-organismos (Ribeiro et al., 2009).

É essencial o CMS em quantidade suficiente para garantir os nutrientes necessários ao atendimento das exigências nutricionais das cabras. Dessa forma, busca-se o conhecimento do valor nutritivo dos alimentos, que pode ser obtido através da composição química, de digestibilidade e pelo próprio desempenho animal, e a partir daí a formulação de dietas balanceadas que possibilite uma melhor eficiência alimentar. Nesse contexto, estudos comprovam que a cana-de-açúcar apresenta resultados promissores com base em índices produtivos e econômicos (Queiroz et al., 2008; Pinto et al., 2010; Romam et al., 2011), todavia pode tornar-se uma realidade alimentar para caprinos leiteiros. Ainda são incipientes os trabalhos encontrados na literatura utilizando-se a cana-de-açúcar como volumoso para esses animais.

Este trabalho foi realizado com o objetivo de avaliar os efeitos da substituição do feno de capim-tifton 85 por diferentes níveis de cana-deaçúcar, na alimentação de cabras em lactação da raça Saanen, sobre o consumo e digestibilidade dos nutrientes.

\section{MATERIAL E MÉTODOS}

O experimento foi conduzido no setor de Caprinovinocultura do Departamento de Zootecnia da Universidade Federal Rural de Pernambuco - UFRPE. Foram utilizadas cabras da raça Saanen com peso vivo (PV) de $47,98 \pm 6,63 \mathrm{~kg}$, distribuídas em quadrado latino $5 \times 5$.

Os períodos experimentais consistiram em quinze dias cada, sendo os dez primeiros dias para adaptação dos animais às dietas experimentais, e os cinco dias restantes para coleta de dados e amostras. No primeiro dia de cada período experimental e ao final do experimento, as cabras foram pesadas. Realizaram-se as práticas de vacinas contra clostridiose e vermifugação contra endo e ectoparasitas, e durante todo o experimento as cabras permaneceram alojadas individualmente em gaiolas de madeira, medindo $1,10 \mathrm{~m} \times 1,20 \mathrm{~m}$, com piso ripado a $60 \mathrm{~cm}$ do solo, providas de comedouros para fornecimento e controle do consumo de alimentos e bebedouros para fornecimento de água a vontade.

As dietas experimentais apresentaram relação volumoso:concentrado de 45:55. O concentrado foi composto por farelo de soja, fubá de milho, mistura mineral comercial para caprinos e ureia, de acordo com cada tratamento, ao passo que os volumosos utilizados foram o feno de capimtifton 85 e cana-de-açúcar, cujas composições químicas encontram-se na Tabela 1.

Tabela 1. Composição química dos ingredientes das dietas experimentais para cabras Saanen em lactação

\begin{tabular}{lcccc}
\hline \multirow{2}{*}{ Nutrientes } & \multicolumn{3}{c}{ Alimentos } \\
\cline { 2 - 5 } & Cana-de-açúcar & Feno de tifton & Milho moído & Farelo de soja \\
\hline Matéria seca $^{1}$ & 242,0 & 913,0 & 887,0 & 865,0 \\
\hline Matéria orgânica $^{2}$ & 963,0 & 922,0 & 983,0 & 968,0 \\
Proteína bruta $^{2}$ & 22,0 & 104,0 & 86,0 & 514,0 \\
Fibra em detergente neutro $^{2}$ & 534,0 & 726,0 & 135,0 & 137,0 \\
Fibra em detergente ácido $^{2}$ & 332,0 & 365,0 & 27,0 & 67,0 \\
Extrato etéreo $^{2}$ & 5,0 & 24,0 & 46,0 & 72,0 \\
Matéria mineral $^{2}$ & 37,0 & 78,0 & 17,0 & 33,0 \\
Carboidratos não fibrosos $^{2}$ & 402,0 & 68,0 & 716,0 & 244,0 \\
Lignina $^{2}$ & 42,0 & 37,0 & 3,0 & 2,0 \\
EM (Mcal/kg)* $^{*}$ & 2,88 & 2,45 & 3,84 & 3,59 \\
\hline
\end{tabular}

${ }^{1} \mathrm{~g} / \mathrm{kg}$ de matéria natural; ${ }^{2} \mathrm{~g} / \mathrm{kg}$ de matéria seca. Energia metabolizável*. 
A cana-de-açúcar utilizada foi a $\mathrm{CO}$ 331, variedade desenvolvida pela Estação Experimental de Campos, Rio de Janeiro (Figueiredo et al., 2011). A colheita da cana-deaçúcar foi feita a cada três dias, sendo devidamente armazenada em galpão coberto e arejado; essa forragem foi picada em partículas variando de 1 a $2 \mathrm{~cm}$, com auxílio de uma máquina forrageira, uma hora antes de seu fornecimento às cabras.

As dietas (Tab. 2) mantiveram-se como isonitrogenadas, e foram calculadas para atender às exigências de mantença e produção de leite para cabras com aproximadamente $50 \mathrm{~kg}$ e com produção média de $2,5 \mathrm{~kg}$ de leite/dia, conforme o (Agricultural..., 1993).

Após pesagem do volumoso, procedeu-se à mistura com o concentrado para fornecimento das rações na forma de mistura completa, permitindo, em média, $20 \%$ de sobras do total de MS ofertada. Antes do arraçoamento da manhã, as sobras eram pesadas para ajuste do consumo diário.

Tabela 2. Composição percentual dos ingredientes e composição química das dietas experimentais para cabras Saanen em lactação

\begin{tabular}{|c|c|c|c|c|c|}
\hline \multirow[t]{2}{*}{ Ingredientes $^{1}$} & \multicolumn{5}{|c|}{ Níveis de substituição (\%) } \\
\hline & 0 & 25 & 50 & 75 & 100 \\
\hline Milho moído & 393,7 & 399,5 & 404,5 & 409,6 & 414,8 \\
\hline Farelo de soja & 147,1 & 137,6 & 128,9 & 120,1 & 111,3 \\
\hline Feno de tifton & 450,0 & 337,5 & 225,0 & 112,5 & 00,0 \\
\hline Cana-de-açúcar & 0,0 & 112,5 & 225,0 & 337,5 & 450,0 \\
\hline Mistura mineral & 9,20 & 9,20 & 9,20 & 9,20 & 9,20 \\
\hline Ureia de liberação lenta & 0,0 & 3,70 & 7,40 & 11,1 & 14,7 \\
\hline Componentes & \multicolumn{5}{|c|}{ Composição química } \\
\hline Matéria seca $(\mathrm{g} / \mathrm{kg})^{1}$ & 888,0 & 681,0 & 553,0 & 465,0 & 401,0 \\
\hline Matéria orgânica $^{2}$ & 944,0 & 949,0 & 954,0 & 959,0 & 963,0 \\
\hline Proteína bruta ${ }^{2}$ & 156,0 & 152,0 & 148,0 & 145,0 & 141,0 \\
\hline Extrato etéreo $^{2}$ & 39,0 & 37,0 & 35,0 & 34,0 & 31,0 \\
\hline Matéria mineral $^{2}$ & 55,0 & 51,0 & 46,0 & 41,0 & 37,0 \\
\hline${ }^{\mathrm{cp}}$ Fibra em detergente neutro ${ }^{2}$ & 424,0 & 399,0 & 375,0 & 348,0 & 325,0 \\
\hline Fibra em detergente ácido ${ }^{2}$ & 184,0 & 180,0 & 176,0 & 172,0 & 168,0 \\
\hline Carboidratos não fibrosos ${ }^{2}$ & 326,0 & 367,0 & 392,0 & 426,0 & 458,0 \\
\hline Lignina $^{2}$ & 21,0 & 22,0 & 23,0 & 23,0 & 24,0 \\
\hline Nutrientes digestíveis totais (\%) & 72,78 & 73,46 & 74,15 & 74,83 & 75,52 \\
\hline Energia metabolizável (Mcal/kg) & 2,63 & 2,66 & 2,68 & 2,71 & 2,73 \\
\hline
\end{tabular}

${ }^{1} \mathrm{~g} / \mathrm{kg}$ de matéria natural; ${ }^{2} \mathrm{~g} / \mathrm{kg}$ de matéria seca. ${ }^{\mathrm{cp}}$ Fibra em detergente neutro corrigida para cinza e proteína.

Durante o período de coletas, após a pesagem, retirava-se uma amostra correspondente a $10 \%$ do total das sobras, que era imediatamente préseca, em estufa de circulação forçada de 55 a $65^{\circ} \mathrm{C}$, por 72 horas. Posteriormente formaram-se amostras compostas por animal e por período; em seguida foram moídas em moinho tipo Wiley com peneira de crivo de $1 \mathrm{~mm}$, para realização das análises químicas. O CMS e dos nutrientes foi calculado pela diferença entre as quantidades ofertadas e as sobras.

Os teores de matéria seca (MS), matéria mineral $(\mathrm{MM})$, extrato etéreo (EE), proteína bruta $(\mathrm{PB})$, fibra em detergente neutro (FDN) e da fibra em detergente ácido (FDA) foram determinados de acordo com as metodologias descritas por Silva e Queiroz (2002). Os carboidratos não fibrosos (CNF) foram calculados conforme Detmann e Valadares Filho (2010), através da equação: CNF $(\%)=100-\% \mathrm{MM}-\% \mathrm{EE}-\% \mathrm{FDNcp}-(\% \mathrm{~PB}-$ $\left.\% \mathrm{PR}_{\mathrm{U}}+\% \mathrm{U}\right)$. Os carboidratos totais (CT) foram estimados por intermédio da equação $\mathrm{CT}=100-(\% \mathrm{~PB}+\% \mathrm{EE}+\% \mathrm{MM})($ Sniffen $e t$ al., 1992). A lignina foi determinada empregando-se metodologia descrita por Van Soest (1967), utilizando-se ácido sulfúrico a 72\% no resíduo da FDA. 
Durante os três primeiros dias do período de coletas, no momento da excreção espontânea, foi realizada a coleta das fezes. As amostras foram imediatamente pré-secas, em estufa de ventilação forçada, a $60^{\circ} \mathrm{C}$ por 72 horas, e posteriormente foram formadas amostras compostas por animal e por período.

Para o cálculo do coeficiente de digestibilidade aparente (CDA) dos nutrientes das dietas, foi estimada a produção de matéria seca fecal (PMSF), utilizando-se óxido crômico $\left(\mathrm{Cr}_{2} \mathrm{O}_{3}\right)$ como indicador externo. Foram ofertados $10 \mathrm{~g}$ de óxido crômico diariamente em forma de sachê; $5 \mathrm{~g}$ do indicador foram envolvidos em papel absorvente, e a cada arraçoamento foram fornecidos aos animais via oral, para garantia de sua ingestão completa, com duração total de fornecimento de seis dias, para que fosse atingido o equilíbrio do indicador no trato gastrintestinal do animal.

A determinação da concentração de cromo nas fezes foi feita pela espectrofotometria de absorção atômica, conforme Williams et al. (1962), na qual a digestão das cinzas resultante de $1 \mathrm{~g}$ de amostra parcialmente seca foi feita com $6 \mathrm{~mL}$ de uma solução ácida $(250 \mathrm{~mL}$ de ácido sulfúrico, $250 \mathrm{~mL}$ de ácido ortofosfórico e $50 \mathrm{~mL}$ de solução sulfato de manganês $10 \%$ solução) e $3 \mathrm{~mL}$ de uma solução de bromato de potássio a $4,5 \%$.

A PMSF foi estimada baseando-se na razão entre a quantidade do indicador administrado ao animal e sua concentração nas fezes, a partir da fórmula: Produção fecal $(\mathrm{g} / \mathrm{dia})=$ gramas de indicador ingerido/concentração do indicador nas fezes.

O CDA foi calculado segundo metodologia descrita por Silva e Leão (1979), em que $\mathrm{CDA}=$ (nutriente ingerido - nutriente excretado/nutriente ingerido) x 100 .

Os resultados obtidos para o consumo $\mathrm{e}$ digestibilidade dos nutrientes foram submetidos a análises de variância e regressão utilizando-se o procedimento GML do programa SAS (1999). Foram utilizados os critérios: significância dos coeficientes de regressão a 5\% de probabilidade, coeficiente de determinação $\left(r^{2}\right)$, obtido pela relação entre a soma de quadrados da regressão e a soma de quadrados de tratamentos, além do fator biológico.

\section{RESULTADOS E DISCUSSÃO}

O aumento dos níveis de cana-de-açúcar provocou decréscimo linear $(\mathrm{P}<0,05)$ nos $\mathrm{CMS}$ e CMO (Tab. 3) nas três formas em que foram expressos (kg/dia, g/kg PV e g/kg ${ }^{0,75}$ de PV). As diferenças médias com relação ao consumo em $\mathrm{kg} /$ dia foram 37,4 e $39,1 \%$ para MS e MO, respectivamente, para os animais que receberam a dieta contendo exclusivamente feno de capimtifton 85 e aqueles cuja dieta continha exclusivamente cana-de-açúcar.

A média do CMS de $1,96 \mathrm{~kg} /$ dia para os animais de todos os tratamentos encontra-se adequada com os valores preditos pelo AFRC (Agricultural..., 1993), que é de 2,03kg/dia para cabras lactantes com $2,80 \mathrm{~kg}$ de leite/dia e $50 \mathrm{~kg}$ de peso vivo. Todavia, para os animais que receberam dietas com cana-de-açúcar como volumoso exclusivo, o valor estimado é de $1,94 \mathrm{~kg} / \mathrm{dia}$, e os animais apresentaram $1,50 \mathrm{~kg} / \mathrm{dia}$ para o CMS, mostrando um deficit de $22,68 \%$, indicativo de que as exigências desses animais não foram totalmente supridas.

Segundo Cabral et al. (2008), o baixo CMS de dietas à base de cana-de-açúcar pode estar relacionado à baixa digestibilidade da FDN, o que certamente ocorreu neste estudo. Houve uma redução de 37,50\% no CMS para dieta com cana-de-açúcar como volumoso único em relação à dieta exclusivamente com feno de tifton, e a baixa digestibilidade da FDN apresentou relação direta com o CMS. Nessas condições, aparentemente a retenção de alimentos causa sensação de enchimento no rúmen, provocando redução do CMS. Essa observação foi comprovada por Magalhães et al. (2006), quando estudaram vacas leiteiras alimentadas com canade-açúcar em substituição à silagem de milho e observaram redução na taxa de passagem ruminal de 0,058 para $0,053 / \mathrm{h}$ à medida que houve total substituição. 
Tabela 3. Consumo e digestibilidade dos nutrientes em função dos níveis de substituição de feno de tifton 85 por cana-de-açúcar para cabras em lactação

\begin{tabular}{|c|c|c|c|c|c|c|c|c|}
\hline Variáveis & 0 & 25 & 50 & 75 & 100 & $\mathrm{EP}^{\#}$ & $r^{2}$ & $\mathrm{~L}^{*}$ \\
\hline \multicolumn{9}{|c|}{ Matéria Seca } \\
\hline Consumo (kg/dia) & 2,3 & 2,3 & 1,9 & 1,5 & 1,4 & 0,0630 & 0,64 & 0,0009 \\
\hline $\mathrm{g} / \mathrm{kg} \mathrm{BW}$ & 4,4 & 4,6 & 3,7 & 3,2 & 2,9 & 1,1569 & 0,60 & 0,0015 \\
\hline $\mathrm{g} / \mathrm{kg} \mathrm{BW}^{0,75}$ & 119,6 & 123,0 & 99,4 & 86,1 & 78,9 & 24,6112 & 0,60 & 0,0012 \\
\hline Digest. (\%) & 0,689 & 0,715 & 0,624 & 0,597 & 0,589 & 1,035 & 0,39 & 0,0350 \\
\hline \multicolumn{9}{|c|}{ Matéria orgânica } \\
\hline Consumo (kg/dia) & 2,3 & 2,3 & 1,9 & 1,5 & 1,4 & 0,0597 & 0,64 & 0,0009 \\
\hline Digest. $(\%)$ & 0,707 & 0,727 & 0,644 & 0,620 & 0,618 & 0,9908 & 0,39 & 0,0429 \\
\hline \multicolumn{9}{|c|}{ Proteína bruta } \\
\hline Consumo (kg/dia) & 0,4 & 0,4 & 0,3 & 0,2 & 0,2 & 0,0101 & 0,70 & 0,0001 \\
\hline Digest. $(\%)$ & 0,821 & 0,828 & 0,762 & 0,789 & 0,825 & 0,6031 & 0,31 & 0,6894 \\
\hline \multicolumn{9}{|c|}{ Extrato etéreo } \\
\hline Consumo (kg/dia) & 0,11 & 0,10 & 0,08 & 0,06 & 0,06 & 0,0025 & 0,70 & 0,0001 \\
\hline Digest. $(\%)$ & 0,806 & 0,758 & 0,715 & 0,586 & 0,624 & 1,2741 & 0,54 & 0,0037 \\
\hline \multicolumn{9}{|c|}{ Carboidratos não fibrosos } \\
\hline Consumo (kg/dia) & 1,3 & 1,3 & 1,2 & 1,1 & 1,0 & 0,0371 & 0,60 & 0,0013 \\
\hline Digest. $(\%)$ & 0,899 & 0,892 & 0,889 & 0,884 & 0,870 & 0,6483 & 0,37 & 0,9797 \\
\hline \multicolumn{9}{|c|}{ Fibra em detergente neutro } \\
\hline Consumo (kg/dia) & 0,87 & 0,89 & 0,65 & 0,51 & 0,41 & 0,0241 & 0,60 & 0,0007 \\
\hline Digest. $(\%)$ & 0,610 & 0,635 & 0,489 & 0,373 & 0,363 & 1,8520 & 0,51 & 0,0052 \\
\hline
\end{tabular}

(P>0.05). \#Erro Padrão. *Efeito linear (L).

O CMS depende de vários fatores, entre os quais a composição e os constituintes da dieta. Assim, outro fator que pode ter contribuído para diminuição no CMS está relacionado às características físicas do alimento e seu teor de umidade. Neste estudo foi observada variação de 319 a $599 \mathrm{~g} / \mathrm{kg}$ de umidade entre as dietas contendo cana-de-açúcar, ao passo que a dieta exclusivamente com feno de capim-tifton 85 apresentou teor de umidade de apenas $112 \mathrm{~g} / \mathrm{kg}$ na MN.

A alta umidade nas dietas com maiores níveis de cana-de-açúcar, associada ao alto teor de carboidratos de fácil digestão, favoreceu a ação microbiana no cocho, com fermentação rápida do alimento, convertendo a glicose em álcool e outros compostos, como ácido acético, propanol e acetaldeído, resultando em odor forte que aparentemente não agradava aos animais.

O consumo de proteína bruta, extrato etéreo, carboidratos não fibrosos e FDN diminuíram linearmente $(\mathrm{P}<0,05)$, seguindo a mesma tendência do consumo de MS (Tab. 3). A concentração de FDN entre as dietas (Tab. 2) diminuiu com a substituição do feno de capimtifton 85 pela cana-de-açúcar. Entretanto, a digestibilidade da fibra também diminuiu, indicativo de que o teor dessa fração de carboidratos fibrosos certamente não foi responsável pela depressão no consumo de MS e demais nutrientes, e sim a qualidade dessa fibra. A digestão dos carboidratos mais complexos constituintes da parede celular da cana-de-açúcar é muito lenta, mostrando-se como o principal fator limitante do consumo de MS. Essa complexidade da parede celular da cana-deaçúcar altera o padrão de fermentação e eficiência microbiana ruminal, o alimento permanece mais tempo no rúmen disposto aos efeitos físicos e à digestão pelos microorganismos, resultando em fina repleção ruminal, determinando a redução do tamanho das partículas e da resposta à digestibilidade dos nutrientes.

A digestibilidade da FDN decresceu linearmente $(\mathrm{P}<0,05)$ com os níveis de substituição. Apresentou-se uma digestibilidade de 0,610\% para dieta exclusivamente com feno de capimtifton 85 como volumoso, enquanto para dieta contendo cana-de-açúcar como único volumoso, a digestibilidade foi de $0,363 \%$, representando uma diminuição de $40,5 \%$ entre o maior e o menor nível de substituição. Corroborando estes resultados, encontram-se na literatura estudos realizados com ruminantes alimentados com 
cana-de-açúcar (Mendonça et al., 2004; Neto et al., 2013).

As dietas apresentaram redução de 23,02\% para a concentração de FDN, ao passo que o teor de lignina aumentou $11,1 \%$ (Tab. 2), fator que também pode ter contribuído para redução na digestibilidade da FDN da cana-de-açúcar, visto que a lignina se liga covalentemente à hemicelulose, formando o complexo ligninacelulose (Van Soest, 1994). Possivelmente, nas dietas com maiores teores de cana-de-açúcar, a cristalinidade da celulose e a hidrofobicidade dos polímeros da lignina inibiram a ação de enzimas microbianas durante o processo de digestão.

Apesar de o teor de CNF ter aumentado 24,5\% com a substituição do feno de capim-tifton 85 por cana-de-açúcar nas dietas, não foi observada diferença significativa $\quad(\mathrm{P}>0,05)$ para digestibilidade, com valor médio de $88,9 \%$ entre as dietas. Independentemente do alimento, esses compostos apresentaram alta digestibilidade no rúmen, podendo ser facilmente atacáveis pelos micro-organismos ruminais (Van Soest, 1967).

\section{CONCLUSÕES}

A substituição do feno de tifton 85 pela cana-deaçúcar nos níveis estudados, na alimentação de cabras Saanen de média a alta produção de leite, torna-se um fator limitante, pois altera o consumo de MS e o desempenho animal; todavia, pode ser utilizada como uma alternativa alimentar.

\section{REFERÊNCIAS}

AGRICULTURAL And Food Research Council - AFRC. Energy and protein requeriments of ruminants. Wallingford: Commonwealth Agricultural Bureaux International, 1993. 159p.

CABRAL, A.M.D.; BATISTA, Â.M.V.; MUSTAFA, A. et al. Performance of dairy goats fed whole sugarcane. Trop. Anim. Heal. Prod., v.41, p.279-283, 2008.

CASTRO, H.S.; ANDRADE, L.A.B.; BOTREL, E.P.; EVANGELISTA, A.R. Rendimentos agrícola e forrageiro de três cultivares de canade-açúcar (Saccharum spp.) em diferentes épocas de corte. Rev. Cienc. agrotec., v.33, p.13361341, 2009.
DETMANN, E. \& VALADARES FILHO, S.C. On the estimation of non-fibrous carbohydrates in feeds and diets. Arq. Bras. Med. Vet. Zootec., v.62, p.980-984, 2010.

FIGUEIREDO, P.; LANDELL, M.G.A.; CAMPANA, M.P. et al. O Instituto Agronômico (IAC) e fatos históricos relacionados ao desenvolvimento da cultura de cana-de-açúcar até o fim do século XX. Campinas: Inst. Agron., Doc. IAC, n.103, 2011. 47p.

GONÇALVES, L.C.; BORGES, I.; FERREIRA, P.D.S. et al. Alimentos para gado de leite. Belo Horizonte: FEPMVZ, 2009. 568p.

MAGALHÃES, A.L.R.; CAMPOS, J.M.S.; CABRAL, L.S.J. et al. Cana-de-açúcar em substituição à silagem de milho para vacas em lactação: parâmetros digestivos e ruminais. Rev. Bras. Zootec., v.35, p.591-599, 2006.

MENDONÇA, S.S.; CAMPOS, J.M.S.; VALADARES FILHO, S.C. et al. Consumo, digestibilidade aparente, produção e composição do leite e variáveis ruminais em vacas leiteiras alimentadas com dietas à base de cana-de-açúcar. Rev. Bras. Zootec., v.33, p.481-492, 2004.

NETO, J.A.F.; REIS, R.B.; SAMPAIO, I.B.M. et al. Produção e composição do leite de vacas alimentadas com cana de açúcar suplementada com fontes de nitrogênio não proteico de diferentes degradabilidades ruminal. Ars Vet., v.29, p.52-59, 2013.

PINTO, A.P.; ABRAHÃO, J.J.S.; MARQUES, J.A. et al. Desempenho e características de carcaça de tourinhos mestiços em confinamento com dietas à base de cana-de-açúcar em substituição à silagem de milho. Rev. Bras. Zootec., v.39, p.198-203, 2010.

QUEIROZ, O.M.; NUSSIO, L.G.; SCHMIDT, P. et al. Silagem de cana-de-açúcar comparada a fontes tradicionais de volumosos suplementares no desempenho de vacas de alta produção. Rev. Bras. Zootec., v.37, p.358-365, 2008.

RIBEIRO, L.S.0.; PIRES, A.J.V.; CARVALHO, G.G.P. et al. Degradabilidade da matéria seca e da fração fibrosa da cana-de-açúcar tratada com hidróxido de sódio ou óxido de cálcio. Rev. Bras. Saúde Prod. Anim., v.10, p.573-585, 2009.

ROMAM, J.; JOBIM, C.C.; RESENDE, F.D. et al. Performance of finishing beef cattle fed different diets containing whole-crop maize silage or sugarcane silage. Rev. Bras. Zootec., v.40, p.682-689, 2011. 
SILVA, D.J. \& QUEIROZ, A.C. Análise de alimentos: métodos químicos e biológicos. 3.ed. Viçosa, MG: Editora UFV, 2002. 235p.

SILVA, J.F.C.; LEÃO, M.I. Fundamentos de nutrição dos ruminantes. Piracicaba: Livroceres, 1979. 380p.

SNIFFEN, C.J.; O'CONNOR, D.J.; VAN SOEST, P.J. et al. A net carbohydrate and protein system for evaluating cattle diets: carbohydrate and protein availability. J. Anim. Sci., v.70, p.3562-3577, 1992.
STATISTICAL Analysis System - SAS. SAS Systems for linear models. Cary: SAS, Institute, 1999. 329p.

VAN SOEST, P.J. Development of a comprehensive system of feeds analysis and its applications to forages. J. Anim. Sci., v.26, p.119-128, 1967.

WILLIAMS, C.H.; DAVID, D.J.; ISMA, A.O. et al. Determination of chromic oxide in faeces samples by atomic absorption spectrophotometry. J. Agric. Sci, v.59, p.381$385,1962$. 